Review

\title{
Recent Developments in Carbon Nanotube Membranes for Water Purification and Gas Separation
}

\author{
Kallista Sears ${ }^{1}{ }^{*}$, Ludovic Dumée ${ }^{1,2}$, Jürg Schütz ${ }^{1}$, Mary She ${ }^{3}$, Chi Huynh ${ }^{1}$,
} Stephen Hawkins ${ }^{1}$, Mikel Duke ${ }^{2}$ and Stephen Gray ${ }^{2}$

1 CSIRO Materials Science and Engineering, Bayview Ave, Clayton Vic 3168, Australia; E-Mails: ludovic.dumee@csiro.au (L.D.); jurg.schutz@csiro.au (J.S.); chi.huynh@csiro.au (C.H.); stephen.hawkins@csiro.au (S.H.)

2 Institute for Sustainability and Innovation, Victoria University, Werribee Campus, Hoppers Lane, Werribee PO Box 14428, Melbourne, Victoria, 8001, Australia; E-Mails: Mikel.Duke@vu.edu.au (M.D.); Stephen.Gray@vu.edu.au (S.G.)

3 Centre for Material and Fibre Innovation, Institute for Technology and Research Innovation, Deakin University, Geelong Vic 3217, Australia; E-Mail: mary.she@deakin.edu.au (M.S.)

* Author to whom correspondence should be addressed; E-Mail: kallista.sears@csiro.au; Tel.: +61-(0)3-95452105; Fax: +61-(0)3-95452363.

Received: 17 November 2009; in revised form: 23 December 2009 / Accepted: 24 December 2009 / Published: 4 January 2010

\begin{abstract}
Carbon nanotubes (CNTs) are nanoscale cylinders of graphene with exceptional properties such as high mechanical strength, high aspect ratio and large specific surface area. To exploit these properties for membranes, macroscopic structures need to be designed with controlled porosity and pore size. This manuscript reviews recent progress on two such structures: (i) CNT Bucky-papers, a non-woven, paper like structure of randomly entangled CNTs, and (ii) isoporous CNT membranes, where the hollow CNT interior acts as a membrane pore. The construction of these two types of membranes will be discussed, characterization and permeance results compared, and some promising applications presented.
\end{abstract}

Keywords: carbon nanotube; bucky-paper; membrane; filtration 


\section{Introduction}

Many water and gas purification techniques, such as membrane distillation, reverse osmosis and $\mathrm{CO}_{2}$ removal from natural gas, are reliant on membranes. Consequently, the development of advanced membrane technologies with controlled and novel pore architectures is important for the achievement of more efficient and cost effective purification. Present polymeric membranes are well known to suffer from a trade off between selectivity and permeability, and in some cases are also susceptible to fouling or exhibit low chemical resistance.

Membranes based on carbon nanotubes (CNTs) offer a possible route to overcome these shortcomings with a number of interesting structures emerging [1-12]. CNTs are nanoscale cylinders of rolled-up graphene (Figure 1) and can be capped at one or both ends with a half fullerene [13]. Single walled CNTs (SWNTs) have outer diameters in the range of 1-3 nm with inner diameters of 0.4-2.4 nm (Figure 1). Multi-walled CNTs (MWNTs) can have outer diameters ranging from $\sim 2 \mathrm{~nm}$ (double walled nanotubes) up to $\sim 100 \mathrm{~nm}$ with tens of walls. CNTs exhibit remarkable electrical and thermal conductivity, and are one of the strongest fibers known [14,15]. These properties, combined with their nanoscale dimensions, have led to their intense study for a wide range of applications [16]. However fabricating macroscopic structures which have controlled geometries, porosity and pore shape, is still challenging.

Figure 1. (a) Schematic of a CNT, (b) TEM image of a CNT showing a number of concentric graphitic walls, and (c) a list of selected CNT properties.
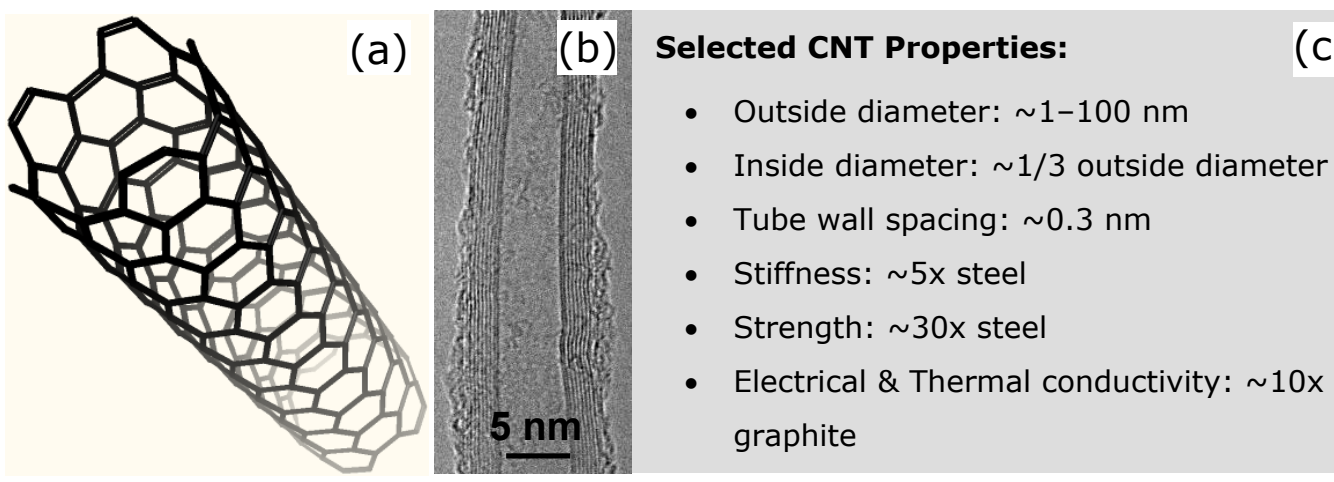

This paper reviews two types of CNT macroscopic structures under consideration for membrane applications: (i) Bucky-paper membranes and (ii) isoporous CNT membranes. These two types of CNT membranes are distinctively different in their structure and arrangement of the CNTs. In the case of a Bucky-paper, the CNTs are randomly arranged into a non-woven, paper-like, structure. This creates a highly porous 3D network with large specific surface area. In contrast, isoporous CNT membranes use aligned CNTs as cylindrical pores across an otherwise impermeable matrix material. These membranes therefore consist of nanoscale CNT pores with a narrowly defined diameter distribution. This paper reviews the various techniques used to fabricate these two types of CNT membranes and the associated challenges. It also discusses how the processing steps affect the final membrane structure, and presents some promising applications for water and/or gas separation. 


\section{Bucky-Paper Membranes}

Due to the simplicity of their preparation, Bucky-papers were one of the first macroscopic structures fabricated from CNTs and their mechanical, electrical and thermal properties have been extensively studied [12,17-22]. The term "Bucky-paper" is used to describe a mat of randomly entangled CNTs prepared by filtration (Figure 2) [21,23] or alternative papermaking processes. CNTs are known to have a strong tendency to aggregate due to van der Waals interactions, and it is these van der Waals interactions which also hold the CNTs together into a cohesive Bucky-paper. Consequently Bucky-papers can be highly flexible and mechanically robust as demonstrated by the origami plane in Figure 2c. Longer, narrower (fewer walled) and more pure nanotubes typically lead to stronger Buckypapers with higher tensile strengths $[18,21,24]$. With increasing MWNT diameter, the attractive van der Waals forces between CNTs become less effective, leading to Bucky-papers with lower tensile strength and poor cohesiveness. This can be improved to some extent through functionalization of MWNTs or the addition of polymers [18].

Figure 2. (a) Process for manufacturing Bucky-papers, (b) SEM image showing the Bucky-paper surface and (c) Bucky-paper origami aeroplane demonstrating their flexibility mechanical robustness.

(a)

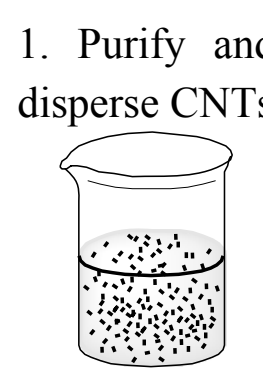

Poorly dispersed dispersed

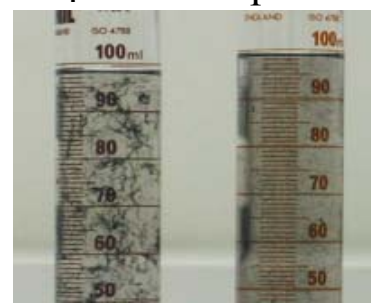

2. Filter the solution

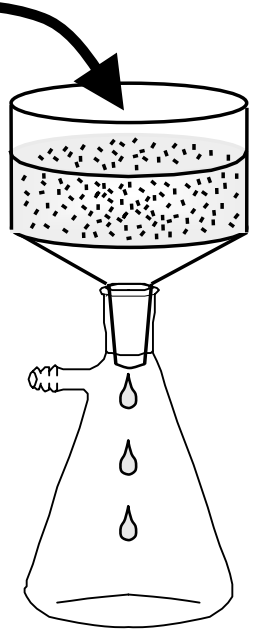

3. Bucky-Paper

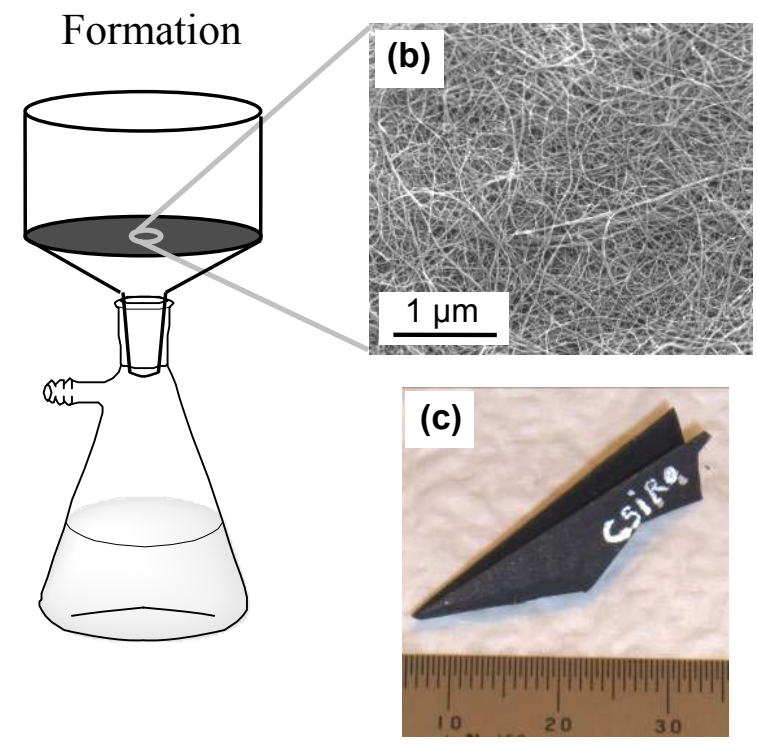

\subsection{Bucky-Paper Processing}

Bucky-papers are typically formed by first purifying the CNTs and then dispersing them in a suitable solvent. Once a well dispersed solution is achieved, it is filtered through a porous support which captures the CNTs to form an optically opaque CNT Bucky-paper (Figure 2). If the Buckypaper is thick enough it can be peeled off the support filter intact.

As prepared CNTs are highly entangled and typically contaminated with impurities. These impurities include the metal catalyst particles, such as Fe, Co and Ni needed for CNT growth, as well as other carbonaceous by-products including amorphous carbon, fullerenes, and graphitic nano- 
particles. The purification and dispersion of CNTs is therefore a critical step in Bucky-paper processing that can affect both the Bucky-paper structure and properties [25-27]. This point is illustrated by Figure 3 which clearly shows the change in Bucky-paper morphology due to differences in the initial CNT dispersion quality.

Figure 3. SEM image showing the surface of a Bucky-paper formed from (a) poorly dispersed single walled carbon nanotubes and (b) well dispersed CNTs $(2 \mathrm{keV}, 9 \mathrm{~mm}$ working distance).
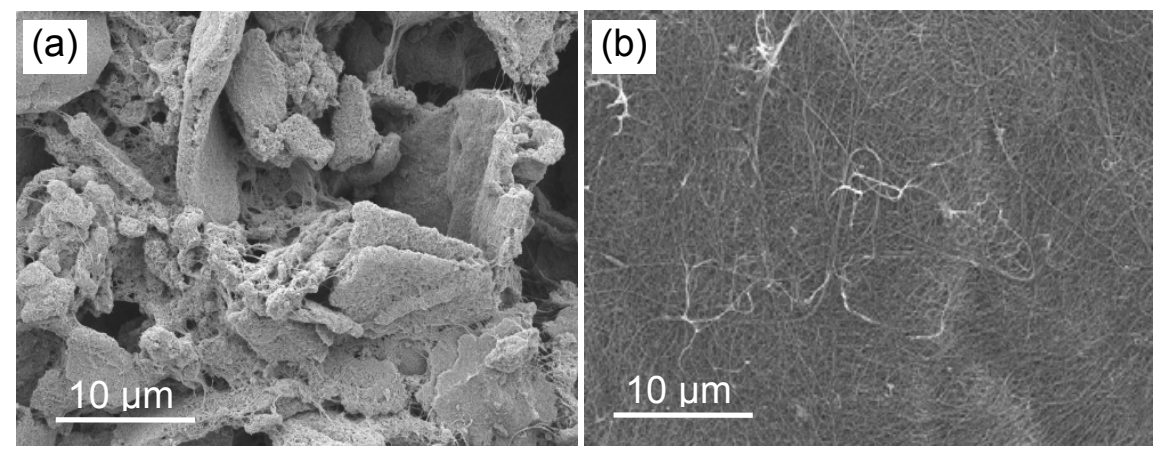

Purification inevitable employs some form of oxidative treatment in combination with physical processes such as filtration and centrifugation [28]. Nitric acid $\left(\mathrm{HNO}_{3}\right)$ or heating in an oxidative environment (e.g., air) is commonly used to remove carbonaceous impurities, which are oxidised at a faster rate than CNTs due to their less perfect graphitic structure. This treatment is often preceded and/or followed by another acid treatment, such as hydrochloric acid $(\mathrm{HCl})$, to remove any metal impurities [24,29-31]. However these purification treatments can also damage and shorten the CNTs, as well as functionalize them with carboxyl and hydroxyl groups rendering them hydrophilic [32,33]. This can advantageous for CNT dispersion into polar solvents such as water. Improved Bucky-paper strength has also been reported following acid treatment and CNT functionalization under controlled conditions [18]. However these purification steps also alter the natural CNT properties, which may not be desirable for the final application.

CNT dispersion typically involves one or a combination of the following the following approaches [34,35]:

(i) covalent functionalization of the CNT surface to improve their chemical compatibility with the dispersing medium [36,37].

(ii) the use of a third component such as a surfactant [34,35,38-40], polymer [41] or biomolecules (such as DNA [42]).

(iii) mechanical treatments such as ultrasonication and shear mixing.

Again, the dispersion steps need to be carefully chosen to suit the type of CNTs and the final application so that the desired CNT properties are not adversely affected [24]. Further details on purification and dispersion techniques can be found in a number of articles and reviews [18,24,34,37,43,44]. 


\subsection{Bucky-Paper Structure and Properties}

As illustrated in Figure 2b, Bucky-papers tend to form a highly porous network of randomly orientated CNTs, although the CNTs predominately lie in a plane parallel to the Bucky-paper surface. The high porosity and random CNT arrangement are particularly evident in movie S1 (supplementary information) which shows a series of TEM images taken with increasing sample tilt from 30 to $150^{\circ}$. Although Bucky-paper membranes do not consist of well defined pores of a single characteristic shape and size, SEM imaging of the surface followed by image analysis, is useful for calculating an "apparent surface" pore size as shown by the histogram and inset of Figure $4[12,45,46]$. The analysis in Figure 4 is for a Bucky-paper fabricated from MWNTs grown by Chemical Vapor Deposition (CVD) that have an average outer diameter and length of $9 \mathrm{~nm}$ and $\sim 300 \mu \mathrm{m}$, respectively (see Table 1-fine CNTs). The CNTs were dispersed in analytical grade isopropanol by repeated sonication and stirring, and then immediately filtered though a poly(ether-sulfone) (PES) support of $0.22 \mu \mathrm{m}$ pore size to form the Bucky-paper. No acid treatment or purification steps were used in order to preserve the CNT's inherent hydrophobicity (see section 2.3.1). The resulting structure was nevertheless of high purity $(>95 \% \mathrm{CNT})$ due to careful choice of the CVD growth technique and parameters. While the average pore size is small, $\sim 25 \mathrm{~nm}$, the pore size distribution is quite broad with a standard deviation of $\sim 14 \mathrm{~nm}$. This is consistent with pore size distributions reported by other groups for similar MWNT Bucky-papers [47], where the average pore size was 29-39 nm with standard deviations of 10-20 nm $[48,49]$. Figure 4 (stars/right axis) also shows results from particle (polystyrene) rejection tests for the same Bucky-paper. These are in reasonable agreement with the pore size distribution determined from SEM with a rejection of $80 \%$ for $100 \mathrm{~nm}$ diameter spheres and $98 \%$ for $500 \mathrm{~nm}$ diameter spheres (not shown).

Figure 4. (Histogram - left axis): Average pore size distribution determined by SEM imaging of a Bucky-paper. (Red stars - right axis): Particle rejection tests with polystyrene spheres.

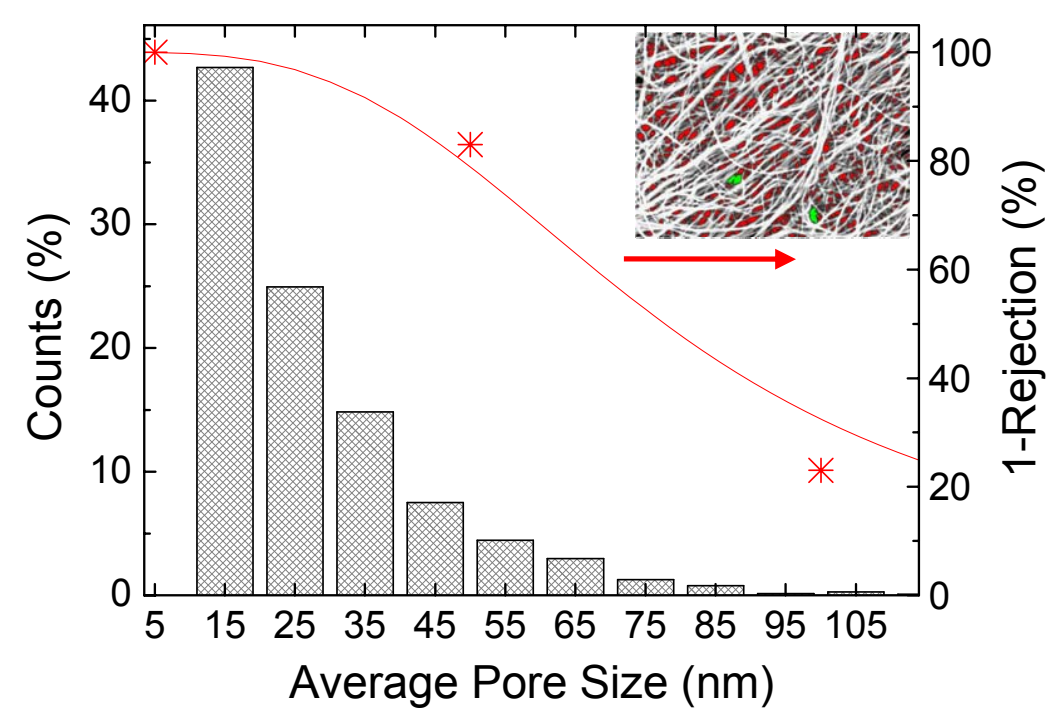


The Bucky-paper pore size is also highly dependent on the type of CNTs used. Figure 5 illustrates how this can be used to tune the average pore size by mixing two types of CNTs in different ratios. The two types of CNTs are referred to as fine $(\sim 9 \mathrm{~nm}$ outer diameter) and coarse $(\sim 37 \mathrm{~nm}$ outer diameter) with reference to their outer diameter and other structural properties (Table 1 and Figure 5b-c). Bucky-papers formed solely from fine or coarse CNTs had an average surface apparent pore size of $\sim 25$ and $49 \mathrm{~nm}$, respectively, while intermediate pore sizes were obtained by using mixtures of the two (Figure 5). Several groups have shown other ways to control porosity and pore size. Kukovecz et al. changed the Bucky-paper pore size through the CNT length, which was varied from $2 \mu \mathrm{m}$ down to $230 \mathrm{~nm}$ through a ball milling treatment [48]. Das et al. controlled the porosity by dispersing polymer beads together with the CNTs to form a Poly(Styrene) (PS)/CNT Bucky-paper composite [50]. The polymer beads were subsequently dissolved creating voids in the Bucky-paper. Figure 6 shows surface and cross-sectional SEM images of a similar composite structure formed by our group using polystyrene beads from Sigma Aldrich (L1528).

Bucky-papers offer incredible porosity and specific surface area. Helium pycnometer measurements made on Bucky-papers fabricated from the fine and coarse CNTs discussed earlier, indicated porosities of $91 \%$ and $87 \%$, respectively. Furthermore Cinke et al. reported a specific surface area as high as $1587 \mathrm{~m}^{2} / \mathrm{g}$ for Bucky-papers formed from SWNTs [29]. They attributed this high surface area to their two step purification process which ensures that the CNTs are de-bundled and highly pure. Figure 7 compares values of specific surface area reported in the literature by plotting them as a function of the CNT outer diameter. As expected a monotonic decrease in the specific surface area is observed with increasing diameter. Since nitrogen cannot penetrate into the space between concentric graphene walls of MWNTs, the specific surface area to CNT mass decreases with increasing CNT outer diameter. The data points represented by open circles in Figure 7 are from CNT samples for which a high impurity content was reported. Judging from the significantly lower surface areas that have been measured for these samples, it seems plausible that the specific surface area is higher once the impurities have been removed.

Table 1. Properties of the coarse and fine carbon nanotubes (CNTs) grown by CVD.

\begin{tabular}{lll}
\hline CNT Type & Coarse & Fine \\
\hline Inner diameter (nm) & $10 \pm 5.5$ & $4.5 \pm 1$ \\
Outer diameter (nm) & $37 \pm 16$ & $9 \pm 1.5$ \\
\# walls & $37 \pm 21$ & $6 \pm 2$ \\
Length $(\boldsymbol{\mu m})$ & $200-400$ & $200-400$ \\
Impurity content & $<10 \mathrm{wt} \%$ & $<5 \mathrm{wt} \%$ \\
\hline
\end{tabular}


Figure 5. (a) Dependence of the Bucky-paper pore size on the ratio of "fine to coarse" carbon nanotubes. The SEM images show the Bucky-paper surface for three different ratios as indicated. (b) and (c) are TEM images $(200 \mathrm{kV})$ of the coarse and fine nanotubes, respectively. The orange arrows indicate catalyst particles within the CNTs. The CNT properties are also summarized in Table 1.

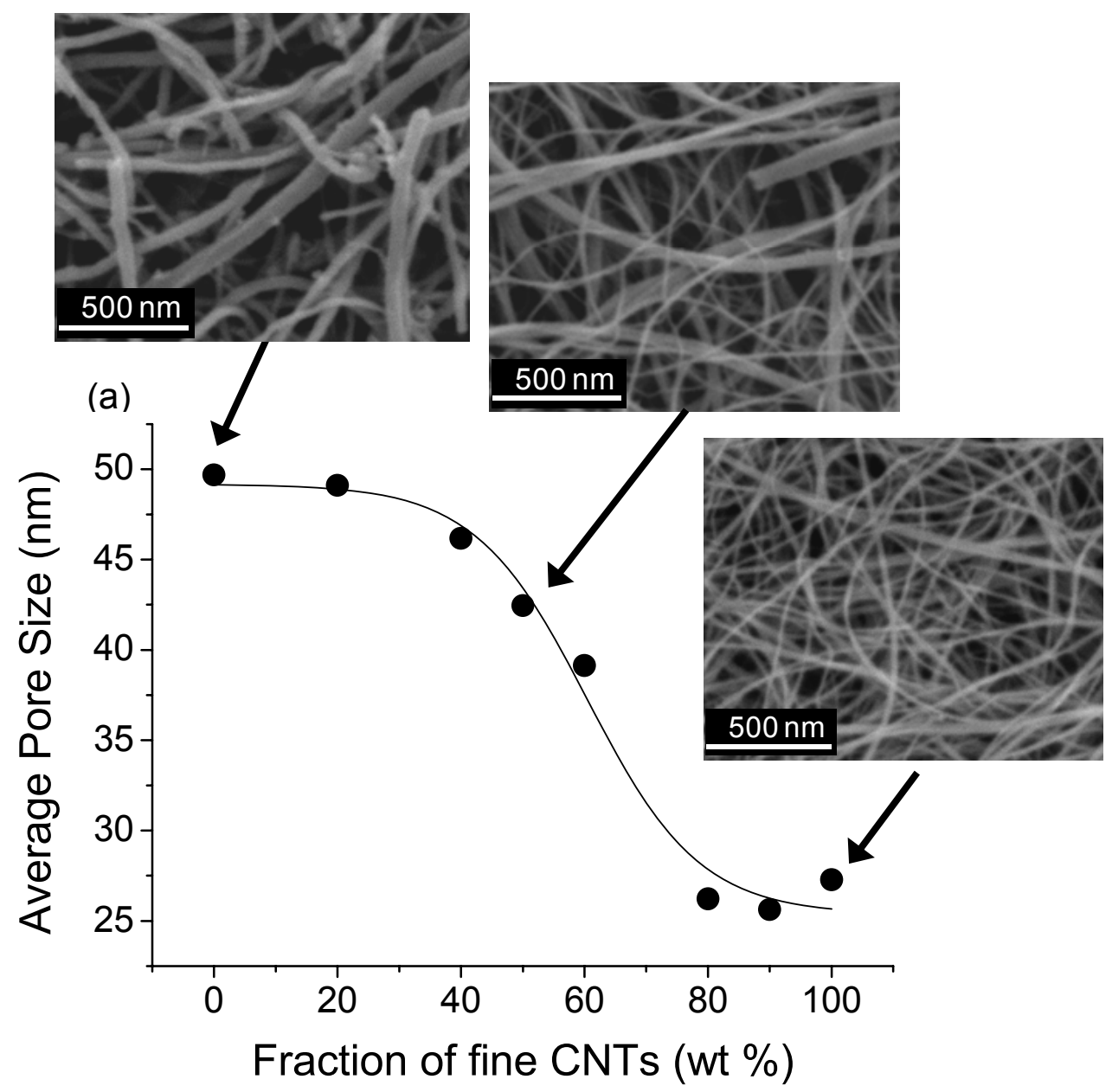

(b) coarse CNTs

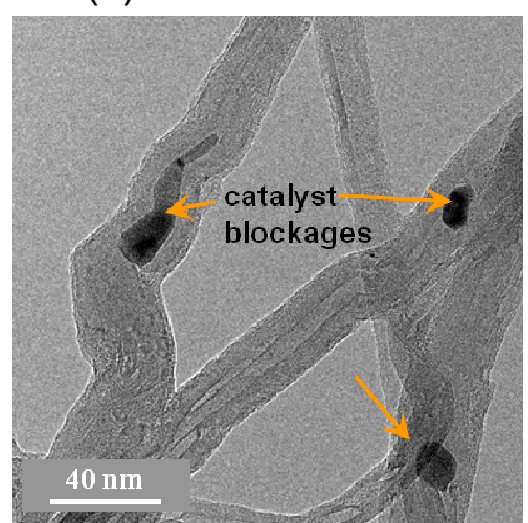

(c) fine CNTs

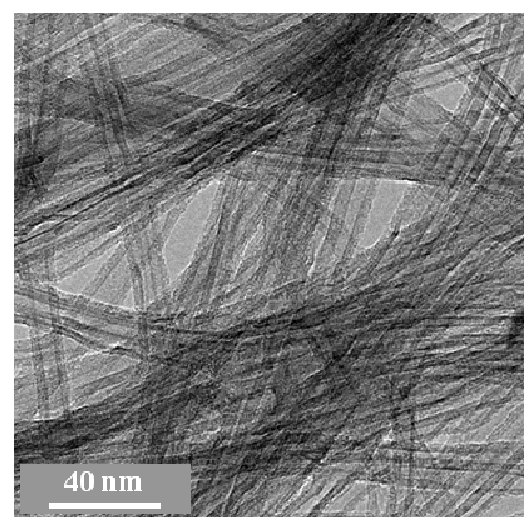


Figure 6. SEM images showing (a) the surface and (b) a cross section (52 ${ }^{\circ}$ sample tilt) of a Bucky-paper formed from a mixed dispersion of PS beads and multi-walled carbon nanotubes ( $5 \mathrm{kV}, 5 \mathrm{~mm}$ working distance). The PS beads in (a) and (b) had $1 \mu \mathrm{m}$ and $100 \mathrm{~nm}$ diameters, respectively. The cross-section was formed by milling with a Gallium Focused Ion Beam.

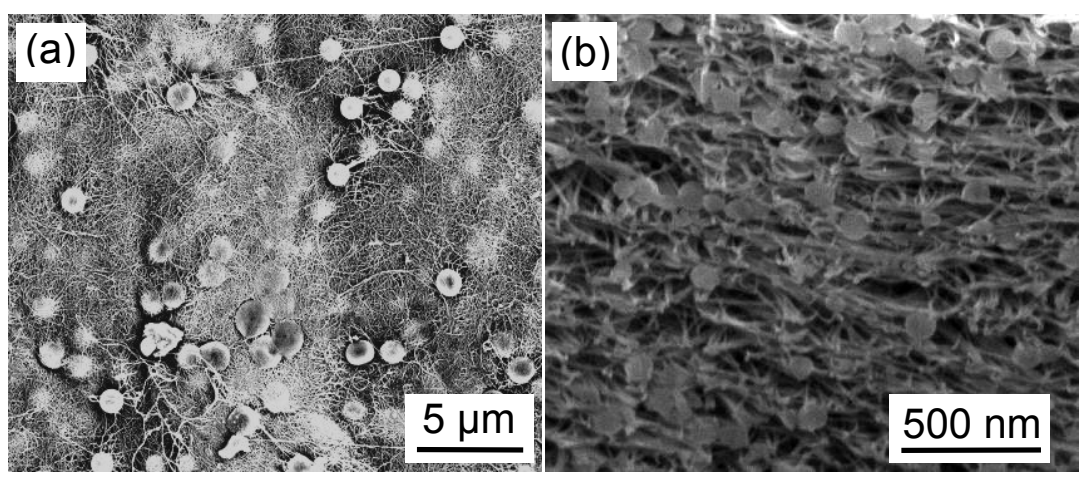

Figure 7. Dependence of carbon nanotube specific surface area on nanotube outer diameter. The data was taken from the literature and supplemented with our own measurements (see Table S1, supplementary materials, for further details and references for the data). The open circles represent results for nanotubes reported to have high impurity content.

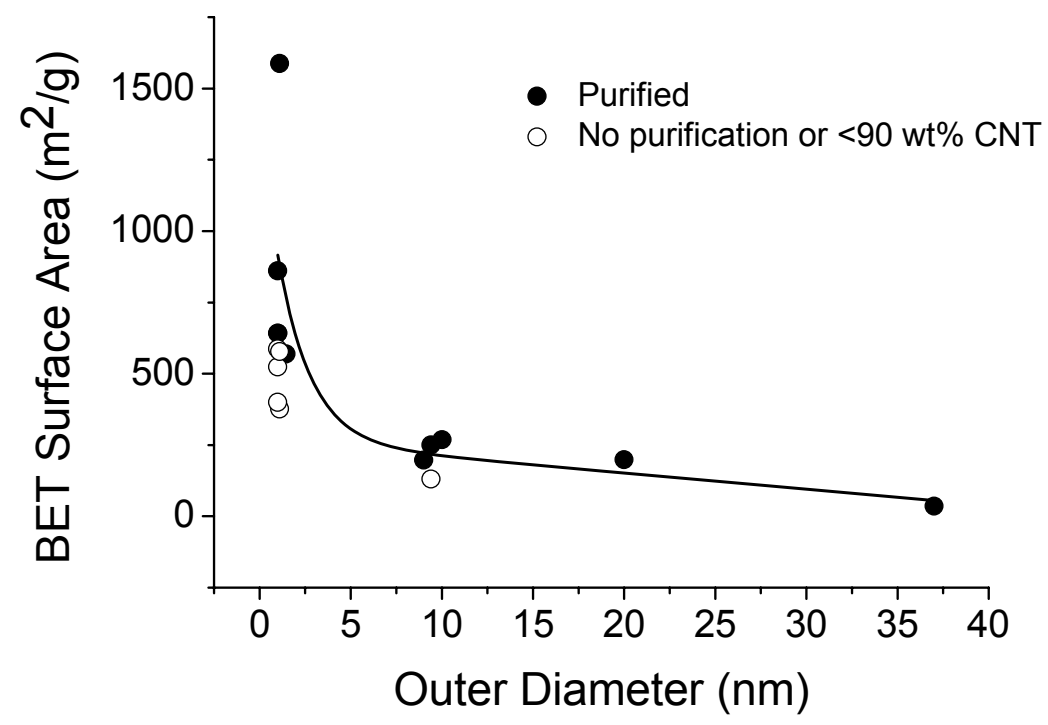

Several authors have investigated methods to introduce CNT alignment in Bucky-papers (Figure 8) [51,52]. Their results indicated enhanced conductivity along the alignment direction and that the porosity and pore structure are also likely to be affected [53,54]. 
Figure 8. SEM image showing the surface of an aligned carbon nanotube Bucky-paper (5 kV, $5 \mathrm{~mm}$ working distance).

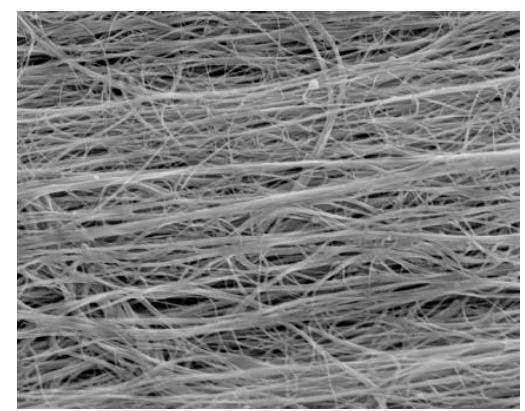

\subsection{Bucky-Papers for Water Purification and Filtration}

\subsubsection{Membrane Distillation}

In terms of the application of Bucky-papers, the authors' work concentrates on their use for water purification by a process called direct contact membrane distillation. This technique is an alternative to reverse osmosis and other desalination techniques, particularly when the concentration of solutes is high [55]. As illustrated in Figure 9, the Bucky-paper is used as a highly hydrophobic membrane to separate a feed of hot sea or brackish water from a permeate of cold fresh water. While liquid cannot cross the air gap formed by the membrane, water vapor is able to pass through the pores from the hot feed to the cold permeate driven by the difference in partial vapor pressure. This vapor then condenses on the permeate side creating fresh water. The inherent hydrophobicity of the nanotubes (D.I. water contact angle $\sim 113^{\circ}$ ) and high Bucky-paper porosity ( $\left.\sim 90 \%\right)$ lend them to this application and we have demonstrated water vapor permeabilities of up to $3.3 \times 10^{-12} \mathrm{~kg} / \mathrm{m} \mathrm{sPa}$ on a small scale rig $[12,45]$. However, cracking of the Bucky-papers with time is a problem as salt water can penetrate into the relatively large cracks and breach the Bucky-paper membrane. This leads to a gradual reduction in permeate quality over time [12]. Figure 10 demonstrates how the vapor flux increases with the difference in partial vapor pressure across the membrane. The two curves in Figure 10 represent results from a pure Bucky-paper (solid circles) and from a composite Bucky-paper (open circles). The composite Bucky-paper was created by vacuum filtering a solution of PVDF through the Bucky-paper structure. The PVDF forms a thin coating on the CNTs which decreases the tendency for the Buckypaper to crack and hence improves its operational lifespan. This however comes at the expense of a lower porosity and hence reduced flux and permeability [45].

Figure 9. Principle behind direct contact membrane distillation.

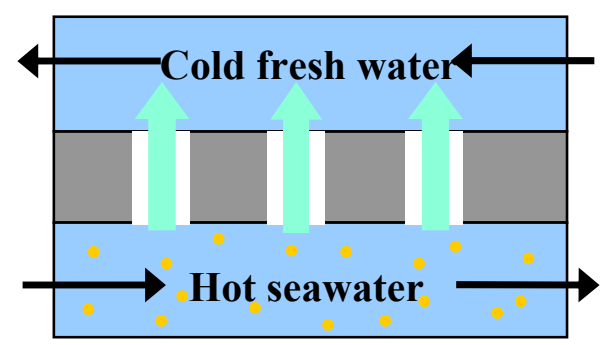


Figure 10. Dependence of water vapor flux on the partial pressure difference across a Bucky-paper membrane in a direct contact membrane distillation setup [stream flux $300 \mathrm{~mL} / \mathrm{min}$; salt concentration $\sim 35 \mathrm{~g} / \mathrm{L} ; \mathrm{T}_{\text {cold }} \sim 5^{\circ} \mathrm{C}, \mathrm{T}_{\text {hot }}$ varied from 25 to $\left.95^{\circ} \mathrm{C}\right]$.

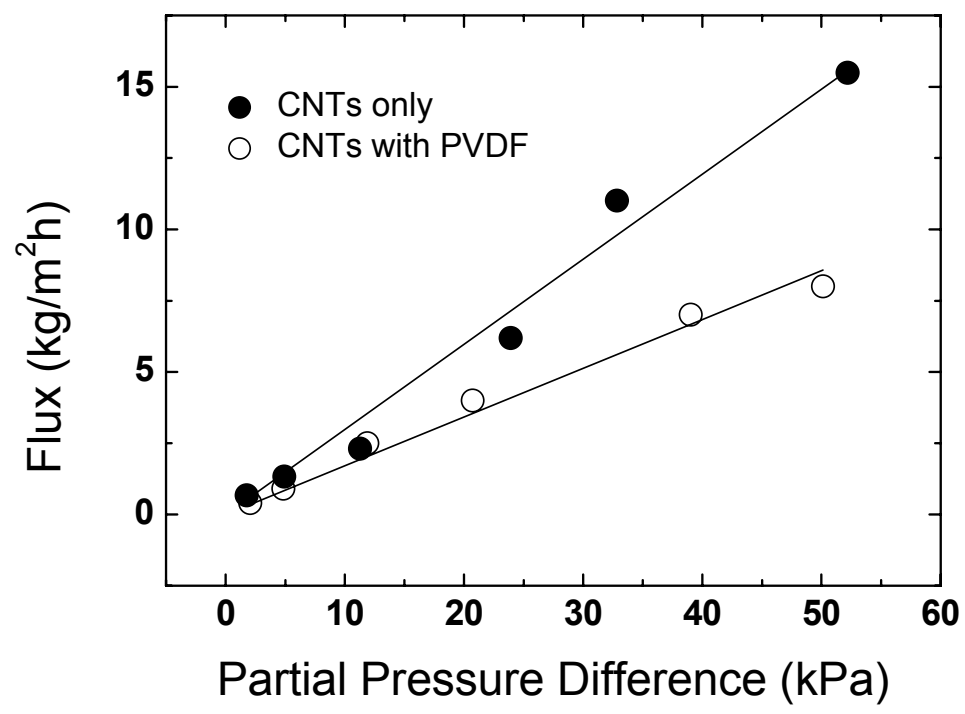

\subsubsection{Other Applications}

Bucky-papers have also been considered for a number of other applications related to filtration and water purification. Several groups have demonstrated desalination of low salinity $(<\sim 5000 \mathrm{mg} / \mathrm{L})$ water using Bucky-paper like structures in a capacitive de-ionization setup [56-60]. This application takes advantage of the electrical conductivity and high porosity offered by Bucky-papers. The setup comprises two electrodes arranged to form a parallel plate capacitor across which a voltage is applied to absorb salt ions of opposite polarity from a stream of salty water. The salt is then released as a concentrated brine when the applied potential is reversed. Wang et al. demonstrated an electrosorption capacity of $\sim 57 \mu \mathrm{mol} / \mathrm{g}$, which was similar to a carbon aerogel electrode despite its lower surface area and is attributed to the more optimal pore size distribution of the Bucky-paper [58].

Bucky-papers have also been used as fine filters. Viswanathan et al. reported that a $2 \mu \mathrm{m}$ thick CNT Bucky-Paper film supported on a cellulose acetate disc was capable of filtering fine particles of 100-500 nm diameter to a level that exceeded the standards set out for HEPA filters [61]. They also suggest that these Bucky-Papers could be used to filter powdered organic dyes and condensed lead fumes.

Antimicrobial properties (in the absence of UV/vis irradiation) and the efficient removal of bacterial from contaminated waters have also been demonstrated [4,62,63]. Brady-Esétvez et al. demonstrated that a SWNT Bucky-paper was effective in completely retaining E. coli cells ( $2 \mu \mathrm{m}$ size) due to size exclusion and also exhibited exceptionally high removal of the model virus MS2 bacteriophage ( $27 \mathrm{~nm}$ diameter) due to depth filtration. Furthermore the SWNT Bucky-paper promoted the inactivation of E. coli cells which was attributed to cell membrane damage on direct contact with SWNT aggregates [62]. Although it is also worth mentioning that other groups have reported fibroblast cell attachment and proliferation on CNT based scaffolds and Bucky-papers [64-67]. 


\section{Isoporous Carbon Nanotube Membranes}

This structure is different from a Bucky-paper in that it uses the CNTs as cylindrical pores across an otherwise impermeable thin film (Figure 11c). This results in a membrane with well controlled nanoporosity with the only route for flow through the hollow CNT interior. These structures are promising for high permeability, high selectivity membranes due to the small CNT diameter (as small as $0.7 \mathrm{~nm}$ ) and predictions of rapid flux through their hollow interior [68-72]. Molecular dynamic simulations have also shown that CNT membranes, in theory, can be used for desalination via reverse osmosis [73].

The predicted rapid flux through CNTs is attributed to two factors. First and foremost is the CNT's smooth, frictionless interior. This is predicted to result in specular, instead of diffusive, collisions between molecules and the CNT wall, leading to enhanced flow for (i) gases in the Knudsen regime $[4,69,70]$ and (ii) pressure driven liquid flow through a pipe (classically described by the HagenPoiseuille law) [74]. Secondly, for CNTs with diameters less than $\sim 2 \mathrm{~nm}$, molecular ordering and single file diffusion have been predicted to lead to the concerted movement of molecules $[68,71,73,75-78]$. In particular, Hummer et al. predicted ballistic motion of water chains through the CNT interior due to strong hydrogen bonding between water molecules and minimal interaction with the CNT wall [68].

Figure 11. Schematic showing the general approach used to construct isoporous CNT membranes.

(a)

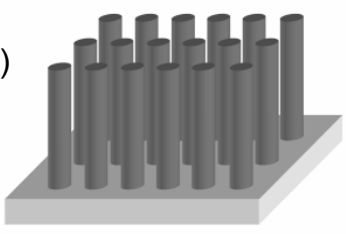

(b)
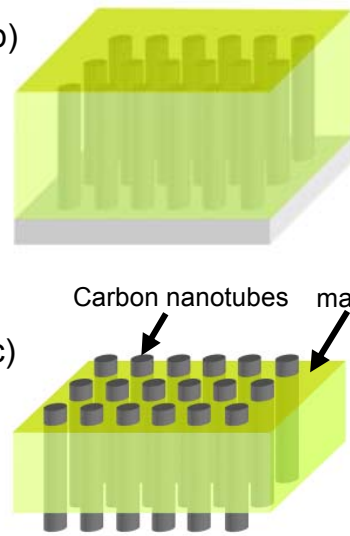

STEP 1: Grow a forest of carbon nanotubes on a substrate.

STEP 2: Infiltrate the spaces between the carbon nanotubes with a matrix material.

STEP 3: Remove the

substrate and open up the carbon nanotubes.

While it is intuitively unfavorable for a polar molecule, such as water, to enter the non-polar interior of a CNT, experimental evidence seems to indicate otherwise [1-3,11,79-84]. One of the first demonstrations of liquid flow through a CNT was by Sun et al. who embedded an individual MWNT (inner diameter $150 \mathrm{~nm}$ ) into an epofix epoxy resin followed by microtoming to form thin membrane slices [80]. However it was the work of two separate groups, Hinds (Majumder) et al. and Holt et al., 
that caught the interest of the scientific community [1-3]. Both groups independently fabricated membranes with a high density of aligned CNT pores and demonstrated fluid flow 2-3 orders of magnitude greater than that predicted by conventional fluid flow theory, although their results have been questioned by some [74]. Both of these groups have also reported functionalization of the CNT tips to gate fluid flow through the CNT pores or enhance their selectivity [85-89]. Since these findings, a number of groups have reported on the construction and permeance of isoporous CNT membranes (Table S2). In the following section the different approaches to membrane construction will be reviewed. While Holt et al. and Hinds et al. are still the only two groups to have reported water flow through the interior of CNT pores, a number of groups have reported permeance for gases. Consequently gas permeance is a useful parameter by which to compare the various approaches to membrane construction and is discussed in section 3.2.

\subsection{Membrane Construction}

For membrane construction, most groups use variations on the general approach outlined in Figure 11 [1,2]. Construction typically begins with a forest of aligned CNTs grown by Chemical Vapor Deposition (CVD) on either a silicon or quartz substrate (Figure 12). The growth parameters need to be carefully chosen so that the CNTs are free from structural blockages such as catalyst particles or bamboo type structures, which could prevent flow through the CNT interior [90]. Once a CNT forest is grown, the spaces between CNTs are infiltrated with an impermeable material to form a continuous matrix. Finally, the excess matrix material and substrate are removed, opening up the CNT ends.

Figure 12. SEM images of a CNT forest grown by chemical vapor deposition on a silicon substrate: (a) low magnification $\left(\sim 35^{\circ}\right.$ sample tilt) and (b) higher magnification $(2 \mathrm{kV}$, $9 \mathrm{~mm}$ working distance).

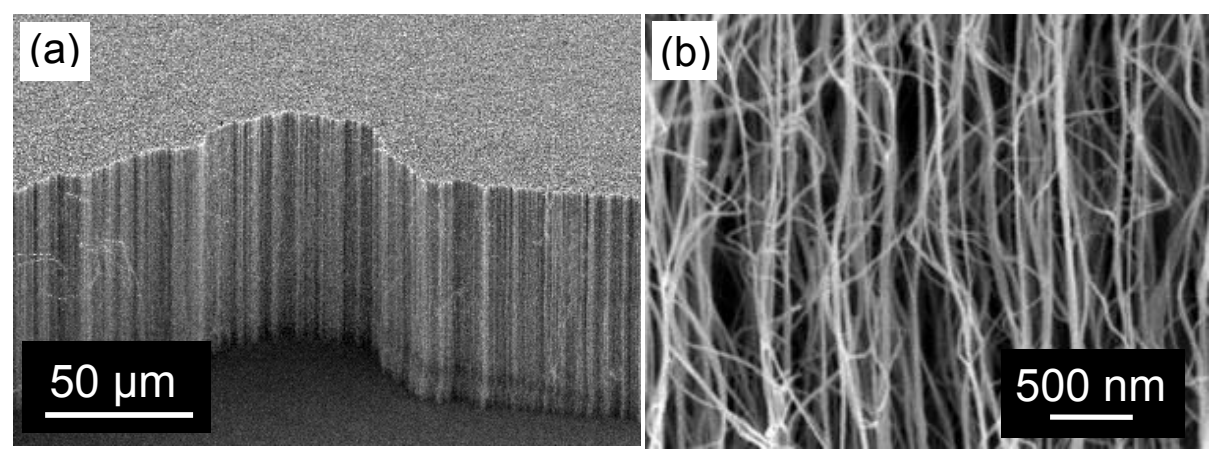

In our method we form a matrix by infiltrating the CNT forest with a two part, low viscosity epoxy followed by curing at $80-120{ }^{\circ} \mathrm{C}$ [91]. Most importantly, the matrix needs to be void free, while at the same time preserving the CNT alignment. Figure 13 shows SEM and TEM images of one of our CNT forests after embedding with epoxy. Clearly, the epoxy conforms well to the CNTs without any obvious cracks or voids. Due to surface tension effects during infiltration, the CNTs are densified into columns (bright contrast) creating CNT free regions in between (Figure 13a). However the forest height before and after infiltration remains the same indicating that the CNT alignment is largely 
maintained. To further investigate the degree of CNT alignment, Raman spectra were measured for an as grown forest and one which had been epoxy infiltrated (Figure 14). The Raman intensity is sensitive to the CNT alignment and is strongest for incident light polarized parallel to the CNT axis [92-94]. A qualitative measure of the CNT alignment is therefore possible by measuring the intensity ratio, $I_{\mid /} / I_{\perp}$, for parallel and perpendicularly polarized light. Values of 3 and 2 were determined for the as grown and epoxy infiltrated forests respectively, indicating some loss of alignment. Vapor phase infiltration, such as that used by Holt et al., may better preserve the CNT alignment [1].

Figure 13. Images of a CNT forest after infiltrating with epoxy (a) SEM image of a liquid nitrogen fractured cross-section. The CNTs are compacted slightly into columns (bright regions) due to surface tension effects, leaving CNT free regions (dark) in between. (b) TEM image (sample prepared by focus ion beam milling). The contrast between the CNTs and epoxy is low due to their similar carbon based composition.
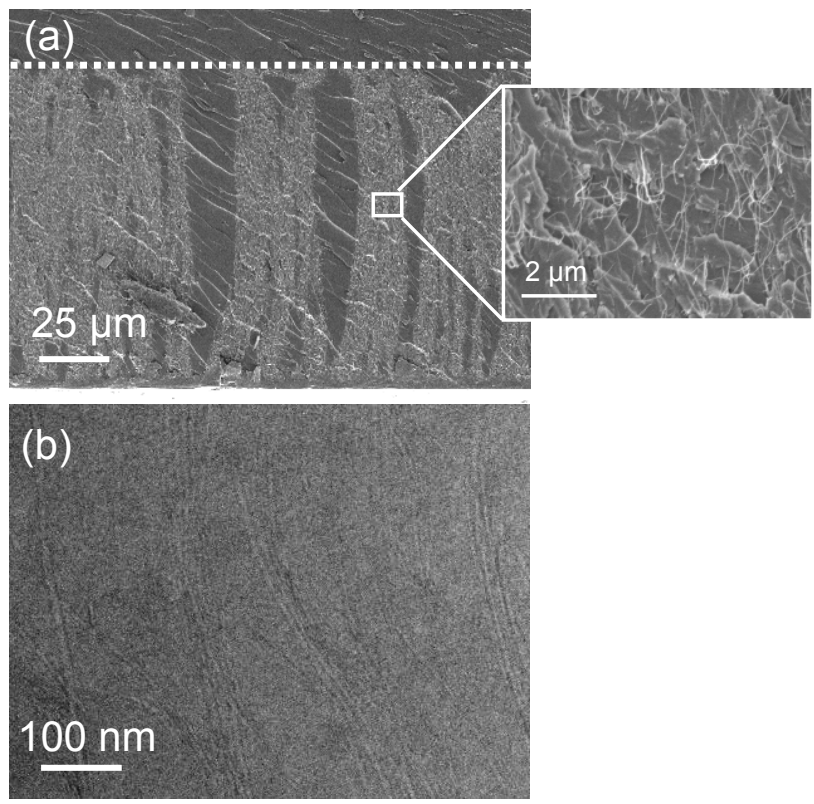

To remove the excess matrix material and open up the CNTs a number of treatments have been employed, such as polishing, acid treatment and oxygen $\left(\mathrm{H}_{2} \mathrm{O}\right.$ or $\left.\mathrm{O}_{2}\right)$ based high frequency plasma treatments (at $13.56 \mathrm{MHz}$ ) [1,2,10]. Figure 15 shows SEM images of our epoxy infiltrated forest after first polishing with diamond paste and then plasma etching with a 30\% $\mathrm{O}_{2} / \mathrm{Ar}$ mixture. Few CNTs (bright contrast) are visible after polishing, while many more are exposed by the plasma treatment (Figure 15b). This is reflected in the air permeance which increased by an order of magnitude from $\sim 1 \times 10^{-10}$ to $\sim 1 \times 10^{-9} \mathrm{moles} / \mathrm{m}^{2} / \mathrm{s} / \mathrm{Pa}$ after plasma treatment. However this is still an order of magnitude lower than that predicted by Knudsen diffusion for a CNT density of $5 \times 10^{10} \mathrm{~cm}^{-2}$, based on the as grown CNT forest, indicating that the majority of CNTs are not yet contributing to permeance and further treatments are necessary.

A number of groups have taken slightly different approaches to that outlined in Figure 11. Mi et al. grew the initial CNT forest directly onto a macroporous alumina substrate [10]. The alumina substrate acts as a support for the final CNT membrane and avoids the etching or polishing step required for 
non-porous silicon or quartz substrates. However it comes at the expense of a reduced CNT density which is reflected in the gas permeance discussed in Section 3.2.

Figure 14. Raman spectra taken from (a) an as grown CNT forest and (b) a forest after infiltrating with epoxy. Both the $\mathrm{D}\left(1,310 \mathrm{~cm}^{-1}\right)$ and $\mathrm{G}\left(1,590 \mathrm{~cm}^{-1}\right)$ bands are present. The Raman signal intensity is sensitive to the CNT alignment and is strongest when the incident polarization is parallel to the CNT axis. It can therefore give an indication of the CNT alignment. A $783 \mathrm{~nm}$ laser with incident power of $2 \times 10^{4} \mathrm{~W} / \mathrm{cm}^{2}$ was used to avoid luminescence from the epoxy resin (see supplementary material).

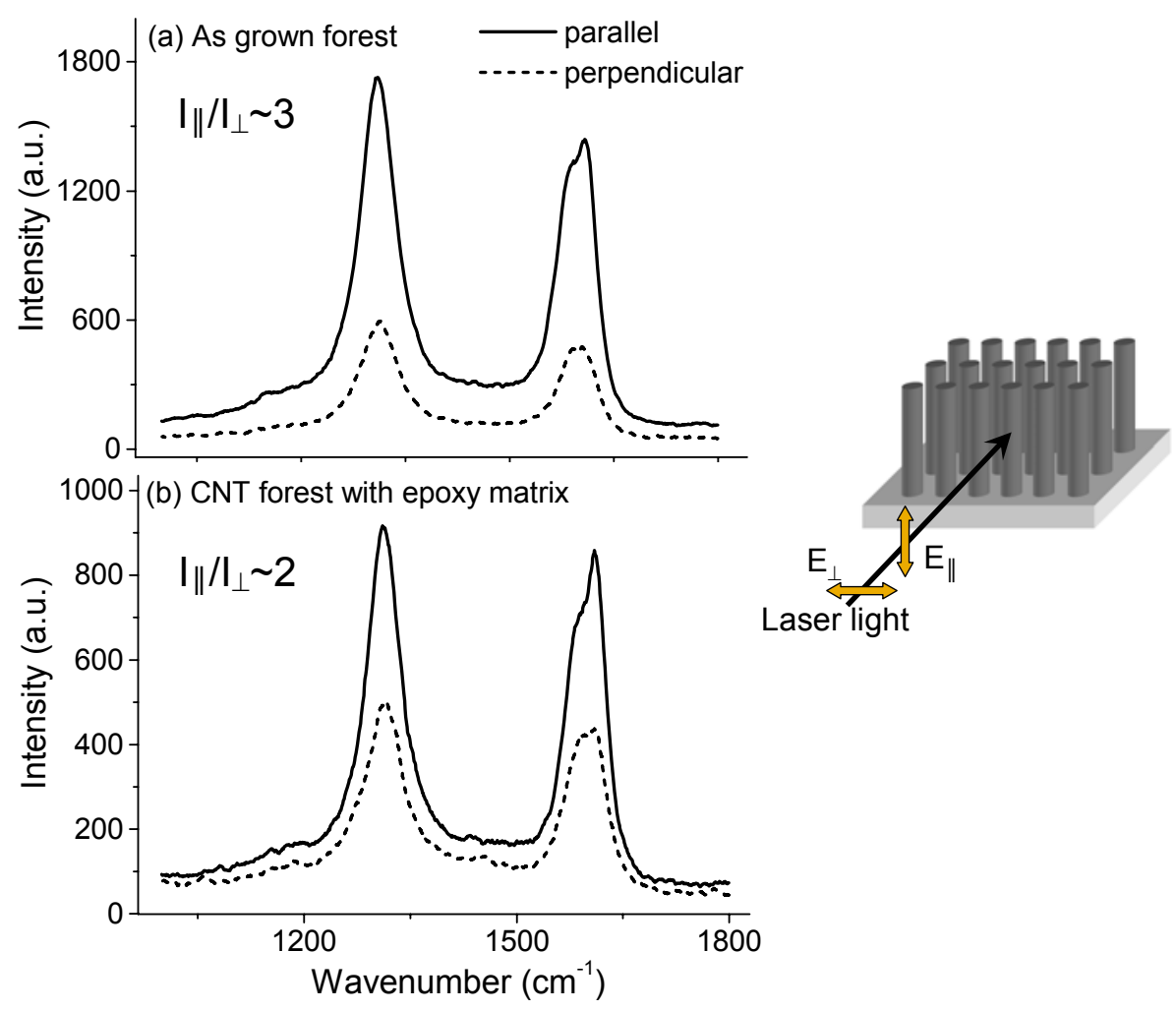

Figure 15. SEM images showing the CNT membrane surface after (a) polishing and (b) a 4 hour plasma treatment with a mixture of $30 \% \mathrm{O}_{2}$ in Argon. The high frequency plasma treatments were performed at a pressure of 0.6 mbar and power of $80 \mathrm{~W}$ in a Pico PC system from Diener Electronics.

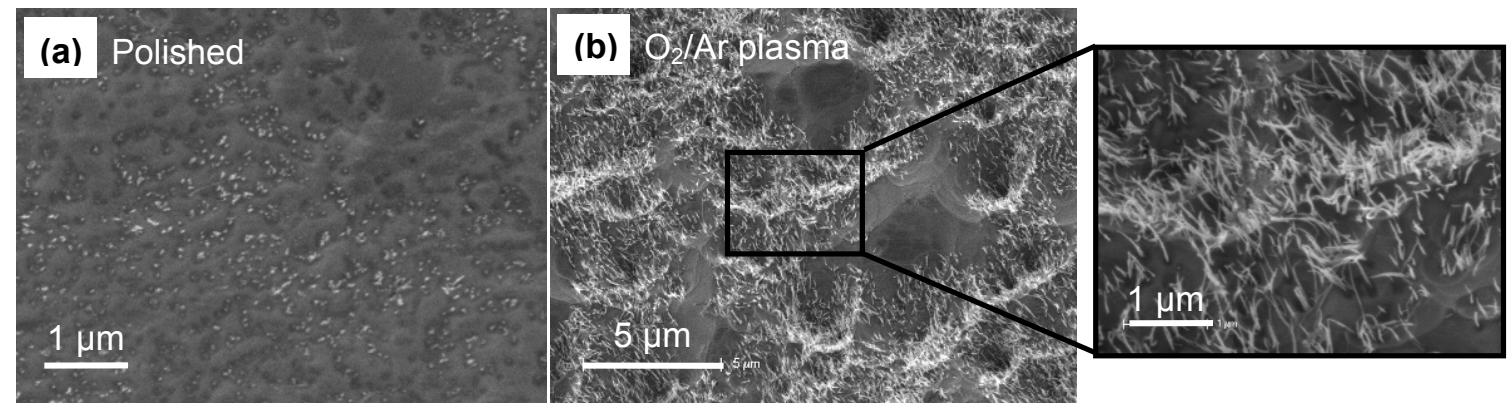


Even at a typical forest density of $10^{11} \mathrm{~cm}^{-2}$ and a CNT inner diameter of $5 \mathrm{~nm}$, the total CNT areal coverage and hence porosity is less than $2 \%$. To improve the available area for permeation, Yu et al. fabricated a dense block of aligned CNTs by shrinking an as grown CNT forest [95]. To shrink the forest they first detached it from the substrate by a water etching step and then collapsed it into a single block using the capillary forces generated by solvent evaporation [96,97]. Yu et al. did not apply a matrix material to the condensed forest so that fluid flow is possible through both the CNT interior and gaps between CNTs, which they estimated were less than $3 \mathrm{~nm}$ [95].

Kim et al. have reported on a scalable method of fabricating membranes which involves first dispersing amine-functionalized CNTs in tetrahydrofuran (THF) and filtering this solution through a porous PTFE substrate [6]. The CNTs appear to spontaneously align themselves perpendicular to the porous PTFE substrate in the draft of the fluid. These CNTs are then embedded in a polysulfone layer. Surprisingly, the polysulfone layer does not seem to block all of the CNTs as they report gas permeance without applying further surface treatments.

Finally, an approach used by several other groups is to grow CNTs within the pores of an anodized alumina template. This leads to forests of vertically aligned, straight CNTs within an alumina matrix. However it appears that these CNTs are only semi-graphitic [11,79,98,99]. As such they do not possess the inherent smoothness and hydrophobicity of a purely graphitic CNT and may not exhibit the same fluid flow properties.

\subsection{Gas Permeance}

Gas permeance is a useful method for evaluating membrane performance and is compared in Table S2 and Figure 16a for the different isoporous CNT membranes discussed above. Here we define permeance as the flux through the membrane divided by the membrane area and the differential pressure. The comparison in Figure 16a suggests that membrane permeance is most affected by the CNT pore density. For example, the highest permeance in Figure 16a is for the membrane reported by $\mathrm{Yu}$ et al. which was formed by densifying an as grown forest [95]. In contrast the membrane structure reported by Mi et al., which was based on a low density CNT forest, has a permeance three orders of magnitude lower [10].

Figure 16 also shows permeance results for three track etched polycarbonate (PC) membranes with 10, 15 and $30 \mathrm{~nm}$ diameter pores. The 10 and $30 \mathrm{~nm}$ membranes were measured by the authors while the value for the $15 \mathrm{~nm}$ PC membrane was taken from Holt et al. [1]. The PC membranes consist of well defined cylindrical pores and therefore offer an ideal benchmark for the CNT membranes. Despite the smaller CNT diameter, the CNT membranes are able to achieve a similar if not better permeance than the PC membranes. For example, the gas permeance for CNT membranes reported by Yu, Holt and Kim are $\sim 200, \sim 20$ and $\sim 2$ times that of a commercial $10 \mathrm{~nm}$ PC membrane, respectively. This is possible, in part, due to a higher CNT pore density compared to PC. As discussed below in relation to the enhancement factor, the atomically smooth and hydrophobic surface of CNTs may also contribute to their high gas permeance, especially for small diameter CNTs $(<\sim 2 \mathrm{~nm})$. 
Figure 16. Summary of gas permeance values reported in the literature for isoporous CNT membranes: (a) Permeance and (b) Enhancement Factor which is defined as the measured permeance divided by the permeance predicted assuming Knudsen flow. An enhancement value is not given for $\mathrm{Yu}$ et al. as gas flow is through both the CNT hollow interior and gaps between CNTs. The last three cross-hatched bars are for polycarbonate track etched membranes. PC10 and PC 30 were measured by the authors, while PC15 is taken from [1]. The pore diameter (in $\mathrm{nm}$ ) is given after the name of each group.

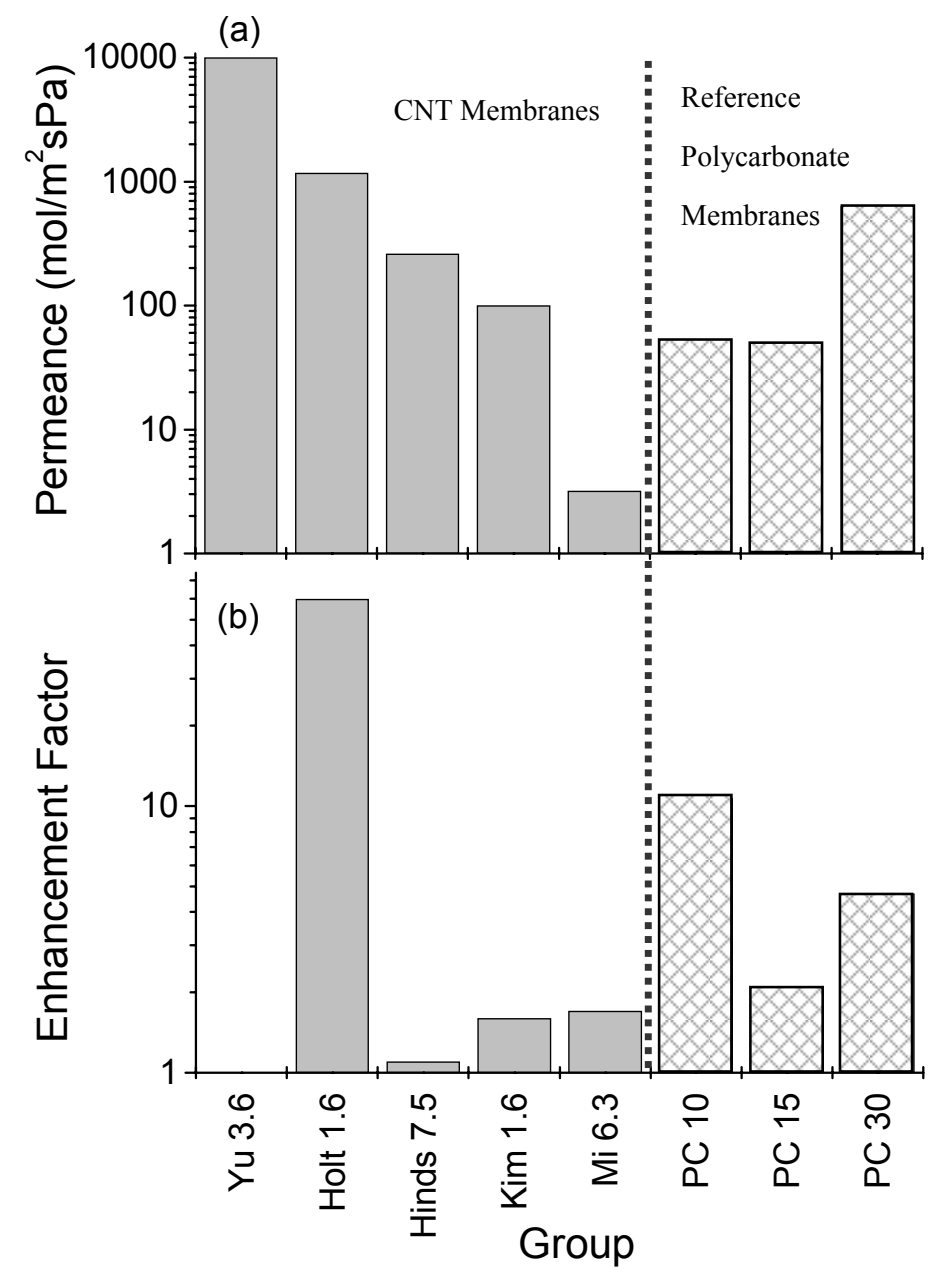

Figure $16 \mathrm{~b}$ compares the enhancement factor for the same CNT membranes and enables a more direct comparison between them as it takes into account differences in membrane thickness, CNT diameter and CNT density. The enhancement factor is defined here as the experimental permeance (plotted in Figure 16a) divided by the permeance predicted from Knudsen theory. Knudsen diffusion applies when the mean free path divided by pore radius is greater than one, which is the case for all of the membranes reviewed here (see Table S2). In the Knudsen regime, there are more collisions with the CNT wall than with other molecules and the permeance, $f_{k}\left[\mathrm{moles} / \mathrm{m}^{2} / \mathrm{s} / \mathrm{Pa}\right]$ is given by:

$$
f_{K}=\frac{\varphi}{3} \sqrt{\frac{8}{\pi R T M}} \frac{1}{\tau L} \rho_{\text {pores }} \times A_{\text {pore }}
$$

where $\varphi[\mathrm{m}]$ is the CNT diameter, $R\left[\mathrm{~J}^{\text {moles }}{ }^{-1} \mathrm{~K}^{-1}\right]$ is the universal gas constant, $T[\mathrm{~K}]$ is the temperature, $M[\mathrm{~kg} / \mathrm{mole}]$ is the gas molecular weight, $\tau$ is the pore tortuosity, $L[\mathrm{~m}]$ is the membrane 
thickness, $\rho_{\text {pores }}\left[\mathrm{m}^{-2}\right]$ is the density of pores, and $\mathrm{A}_{\text {pore }}\left[\mathrm{m}^{2}\right]$ is the inner area of each CNT pore and is equal to $\pi \varphi^{2} / 4$. The biggest uncertainty in determining the enhancement factor lies in an accurate knowledge of the density of CNTs contributing the membrane's permeance. Typically SEM or TEM imaging has been used to estimate an upper value $[1,6,10]$.

The enhancement factor lies between 1-2 for most of the CNT membranes (Figure 16b), which is in reasonable agreement with Knudsen diffusion considering the uncertainty linked to many of the input values, in particular the CNT density. The exception to this is Holt et al. who report a phenomenal enhancement factor of $\sim 60$ [1]. This enhancement over Knudsen diffusion in likely due their sophisticated fabrication route, which may ensure a greater percentage of open CNTs, in combination with the small CNT diameter used, $1.6 \mathrm{~nm}$. For small CNT diameters, enhanced flow rates are predicted due to nano-scale confinement and the smooth, hydrophobic CNT interior [68,72]. Interestingly, the PC membranes show enhancement factors between 2-10. This may be due to a nonuniform pore diameter throughout the membrane thickness. Alternatively, other non-Knudsen transport mechanisms such as viscous flow may also be contributing to their permeance.

In terms of gas separation, most reported studies found that the single-component selectivity exhibited an inverse-square-root scaling with molecular mass, characteristic of Knudsen diffusion $[1,6,10,95]$. Holt et al. found that hydrocarbons were an exception to this and exhibited higher selectivities [1]. This was attributed to the preferential interaction of hydrocarbons with the CNT internal walls and possibly surface diffusion. Hence it may be possible to separate mixtures such as $\mathrm{CO}_{2} / \mathrm{CH}_{4}$ through this mechanism.

\section{Conclusions}

In summary, this paper has reviewed the fabrication and application of two types of CNT based membranes (i) Bucky-papers and (ii) isoporous CNT membranes. Both of these membranes have distinctively different structures and porosity. Bucky-paper membranes are comprised of randomly entangled CNTs that are fabricated by a relatively simple process involving vacuum filtration. The Bucky-paper properties depend on the type of CNTs used and their pre-treatment (purification and dispersion). They typically offer a highly porous structure with large specific surface area. As such they are of interest for applications such as direct contact membrane distillation, capacitive deionization, and filtration of particles including bacteria and viruses. In contrast, isoporous CNT membranes use the CNTs as pores across an otherwise impermeable matrix material. A handful of groups have published different approaches to isoporous CNT membrane construction with promising permeance results. Despite the smaller CNT diameter, gas permeances equal to or higher than that of commercial polycarbonate membranes with cylindrical, $10 \mathrm{~nm}$ diameter pores, have been reported. This is made possible, in part, by a higher CNT pore density compared to polycarbonate membranes. However, as demonstrated by Holt et al., flow enhancement due to the atomically smooth and hydrophobic CNT surface may also play a large role for CNT pore diameters less than $\sim 2 \mathrm{~nm}$. Several groups have also demonstrated fast liquid flow through the CNT interior, 2-3 orders of magnitude greater than that predicted by conventional theory, and seem to confirm theoretical predictions. These isoporous membranes are therefore of great interest for nanofiltration membranes with both high flux 
and selectivity. One of the major challenges lies in fabricating large scale isoporous CNT membranes, while still maintaining their structural integrity.

\section{Acknowledgements}

We wish to acknowledge the expert advice and assistance of John Ward and Mark Greaves on SEM, and Sergey Rubanov and Kenneth Goldie at Bio 21 for assistance with focused ion beam milling. We are also grateful to Lingxue Kong for helping to establish collaborations at Deakin University, Chris Skourtis for his image of an aligned CNT Bucky-paper, Zongli Xie and Lisa Wong for their help with BET measurements, and Finlay Shanks for assistance with Raman measurements.

\section{Supplementary Materials}

Movie S1 showing TEM images of a Bucky-paper membrane with sample tilts of 30-150'.

Experimental Details, Table S1 and Table S2.

Supplementary materials can be downloaded at http://www.mdpi.com/1996-1944/3/1/127/s1.

\section{References and Notes}

1. Holt, J.K.; Park, H.G.; Wang, Y.; Staderman, M.; Artyukhin, A.B.; Grigoropoulos, C.P.; Noy, A.; Bakajin, O. Fast Mass Transport Through Sub-2-Nanometer Carbon Nanotubes. Science 2006, 312, 1034-1037.

2. Hinds, B.J.; Chopra, N.; Rantell, T.; Andrews, R.; Gavalas, V.; Bachas, L.G. Aligned Multiwalled Carbon Nanotube Membranes. Science 2004, 303, 62-65.

3. Majumder, M.; Chopra, N.; Andrews, R.; Hinds, B.J. Enhanced Flow in Carbon Nanotubes. Nature 2005, 438, 44.

4. Srivastava, A.; Srivastava, O.N.; Talapatra, S.; Vajtai, R.; Ajayan P.M. Carbon Nanotube Filters. Nature 2004, 3, 610-614.

5. Li, X.; Zhu, G.; Dordick, J.S.; Ajayan, P.M. Compression-Modulated Tunable-Pore CarbonNanotube Membrane Filters. Small 2007, 3, 595-599.

6. Kim, S.; Jinschek, J.R.; Chen, H.; Sholl, D.S.; Marand, E. Scalable Fabrication of Carbon Nanotube/Polymer Nanocomposite Membranes for High Flux Gas Transport. Nano Lett. 2007, 7, 2806-2811.

7. Kim, S.; Pechar, T.W.; Marand, E. Poly(imide siloxane) and Carbon Nanotube Mixed Matrix Membranes for Gas Separation. Desalination 2006, 192, 330-339.

8. Peng, F.; Pan, F.; Sun, H.; Lu, L.; Jiang, Z. Novel Nanocomposite Pervaporation Membranes composed of Poly(vinyl alcohol) and Chitosan-Wrapped Carbon Nanotubes. J. Membr. Sci. 2007, 300, 13-19.

9. Peng, F.; Hu, C.; Jiang, Z. Novel Poly(vinyl alcohol)/Carbon Nanotube Hybrid Membranes for Pervaporation Separation of Benzene/Cyclohexane Mixtures. J. Membr. Sci. 2007, 297, 236-242.

10. Mi, W.; Lin, Y. S.; Li, Y. Vertically Aligned Carbon Nanotube Membranes on Macroporous Alumina Supports. J. Membr. Sci. 2007, 304, 1-7. 
11. Whitby, M.; Cagnon, L.; Thanou, M.; Quirke, N. Enhanced Fluid Flow through Nanoscale Carbon Pipes. Nano Lett. 2008, 8, 2632-2637.

12. Dumée, L.F.; Sears, K.; Schütz, J.; Finn, N.; Huynh, C.; Hawkins, S.; Duke, M.; Gray, S. Characterisation and Evaluation of Carbon Nanotube Bucky-paper Membranes for Direct Contact Membrane Distillation. J. Membr. Sci. 2009, Submitted.

13. Iijima, S. Helical Microtubules of Graphitic Carbon. Nature 1991, 354, 56-58.

14. O'Connell, M.J. Carbon Nanotubes: Properties and Applications; Taylor \& Francis Group: Boca Raton, FL, USA, 2006.

15. Dresselhaus, M.S.; Dresselhaus, G.; Avouris, Ph. Carbon Nanotubes: Synthesis, Structure, Properties, and Applications; Springer: Berlin, Germany, 2001.

16. Baughman, R.H.; Zakhidov, A.A.; De Heer, W.A. Carbon Nanotubes-the Route toward Applications. Science 2002, 297, 787-792.

17. Zhang, X.; Sreekumar, T.V.; Liu, T.; Kumar, S. Properties and Structure of Nitric Acid Oxidized Single Walled Carbon Nanotube Films. J. Phys. Chem. B 2004, 108, 16435-16440.

18. Xu, G.; Zhang, Q.; Zhou, W.; Huang, J.; Wei, F. The Feasibility of Producing MWCNT Paper and Strong MWCNT Film from VACNT Array. Appl. Phys. A: Mater. Sci. Process. 2008, 92, 531-539.

19. Bandow, S.; Rao, A.M.; Williams, K.A.; Thess, A.; Smalley, R.E.; Eklund, P.C. Purification of Single-Wall Carbon Nanotubes by Microfiltration. J. Phys. Chem. B 1997, 101, 8839-8842.

20. Baughman, R.H.; Cui, C.; Zakhidov, A.A.; Iqbal, Z.; Barisci, J.N.; Spinks G.M.; Wallace, G.G.; Mazzoldi, A.; Rossi D.D.; Rinzler, A.G.; Jaschinski, O.; Roth, S.; Kertesz, M. Carbon Nanotube Actuators. Science 1999, 284, 1340-1344.

21. Kim, B.Y.A.; Muramatsu, H.; Hayashi, T.; Endo, M.; Terrones, M.; Dresselhaus, M.S. Fabrication of High Purity, Double-Walled Carbon Nanotube Buckypaper. Chem. Vap. Deposition 2006, 12, 327-330.

22. Park, J.G.; Li, S.; Fan, X.; Zhang, C.; Wang, B. The High Current-Carrying Capacity of Various Carbon Nanotube-Based Buckypapers. Nanotechnology 2008, 19, 185710:1-185710:7.

23. Endo, M.; Muramatsu, H.; Hayashi, T.; Kim, Y.A.; Terrones, M.; Dresselhaus, M.S. 'Buckypaper' from Coaxial Nanotubes. Nature 2005, 433, 476.

24. Park, T.J.; Banerjee, S.; Hemraj-Benny, T.; Wong, S.S. Purification Strategies and Purity Visualization for Single-Walled Carbon Nanotubes. J. Mater. Chem. 2006, 16, 141-154.

25. Suppiger, D.; Busato, S.; Ermanni, P. Characterization of Single-Walled Carbon Nanotube Mats and their Performance as Electromechanical Actuators. Carbon 2008, 46, 1085-1090.

26. Vohrer, U.; Kolaric, I.; Haque, M.H.; Roth, S.; Detlaff-Weglikowska, U. Carbon Nanotube Sheets for the Use as Artificial Muscles. Carbon 2004, 42, 1159-1164.

27. Rouse, J.H. Polymer-Assisted Dispersion of Single-Walled Carbon Nanotubes in Alcohols and Applicability toward Carbon Nanotube/Sol-Gel Composite Formation. Langmuir 2005, 21, 1055-1061.

28. Bandow, S.; Asaka, S.; Zhao, X.; Ando, Y. Purification and Magnetic Properties of Carbon Nanotubes. Appl. Phys. A: Mater. Sci. Process. 1998, 67, $23-27$.

29. Cinke, M.; Li, J.; Chen, B.; Cassell, A.; Delzeit, L.; Han, J.; Meyyappan, M. Pore Structure of Raw and Purified HiPco Single-Walled Carbon Nanotubes. Chem. Phys. Lett. 2002, 365, 69-74. 
30. Dillon, A.C.; Gennett, T.; Jones, K.M.; Alleman, J.L.; Parilla, P.A.; Heben, M.J. A Simple and Complete Purification of Single-Walled Carbon Nanotube Materials. Adv. Mater. 1999, 11, 1354-1358.

31. Xu, Y.Q.; Peng, H.; Hauge, R.H.; Smalley, R.E. Controlled Multistep Purification of SingleWalled Carbon Nanotubes. Nano Lett. 2005, 5, 163-168.

32. Ziegler, K.J.; Gu, Z.; Peng, H.; Flor, E.L.; Hauge, R.H.; Smalley, R.E. Controlled Oxidative Cutting of Single-Walled Carbon Nanotubes. J. Am. Chem. Soc. 2005, 127, 1541-1547.

33. Hu, H.; Zhao, B.; Itkis, M.E.; Haddon, R.C. Nitric Acid Purification of Single-Walled Carbon Nanotubes. J. Phys. Chem. B 2003, 107, 13838-13842.

34. Vaisman, L.; Wagner, H.D.; Marom, G. The Role of Surfactants in Dispersion of Carbon Nanotubes. Adv. Colloid Interface Sci. 2006, 128-130, 37-46.

35. Sun, Z.; Nicolosi, V.; Rickard, D.; Bergin, S.D.; Aherne, D.; Coleman, J.N. Quantitative Evaluation of Surfactant-Stabilised Single-Walled Carbon Nanotubes:Dispersion Quality and Its Correlation with Zeta Potential. J. Phys. Chem. C 2008, 112, 10692-10699.

36. Shaffer, M.S.P.; Fan, X.; Windle, A.H. Dispersion and Packing of Carbon Nanotubes. Carbon 1998, 36, 1603-1612.

37. Lin, T.; Bajapi, V.; Ji, T.; Dai, L. Chemistry of Carbon Nanotubes. Aust. J. Chem. 2003, 56, $635-651$.

38. Yu, J.; Grossiord, N.; Koning, C.E.; Loos, J. Controlling the Dispersion of Multi-Wall Carbon Nanotubes in Aqueous Surfactant Solution. Carbon 2007, 45, 618-623.

39. Wang, Y.; Gao, L.; Sun, J.; Liu, Y.; Zheng, S.; Kajiura, H.; Li, Y.; Noda, K. An Integrated Route for Purification, Cutting and Dispersion of Single-Walled Carbon Nanotubes. Chem. Phys. Lett. 2006, 432, 205-208.

40. Priya, B.R.; Byrne, H.J. Investigation of Sodium Dodecyl Benzene Sulfonate Assisted Dispersion and Debundling of Single-Walled Carbon Nanotubes. J. Phys. Chem. B 2008, 112, 332-337.

41. Nish, A.; Hwang, J.J.; Doig, J.; Nicholas, R.J. Highly Selective Dispersion of Single-Walled Carbon Nanotubes Using Aromatic Polymers. Nature 2007, 2, 640-646.

42. Zheng, M.; Jagota, A.; Semke, E.D.; Diner, B.A.; Mclean, R.S.; Lustig, S.R.; Richardson, R.E.; Tassis, N.G. DNA-Assisted Dispersion and Separation of Carbon Nanotubes. Nature 2003, 2 , $338-342$.

43. Hou, P.X.; Liu, C.; Cheng, H.-M. Purification of Carbon Nanotubes. Carbon 2008, 46, 2003-2025.

44. Hirsch, A.; Vostrowsky, O. Functionalization of Carbon Nanotubes. Top. Curr. Chem. 2005, 245, 193-237.

45. Dumée, L.; Sears, K.; Schütz, J.; Finn, N.; Duke, M.; Gray., S. Design and Characterisation of Carbon Nanotube Bucky-Paper Membranes for Membrane Distillation. Desalin. Water Treat. 2009, Submitted.

46. Hernández, A.; Calvo, J.I.; Prádanos, P.; Tejerina, F. Pore Size Distributions in Microporous Membranes. A Critical Analysis of the Bubble Point Extended Method. J. Membr. Sci. 1996, 112, 1-12.

47. Smajda, R.; Kukovecz, Á.; Kónya, Z.; Kiricsi, I. Structure and Gas Permeability of Multi-Wall Carbon Nanotube Buckypapers. Carbon 2007, 45, 1176-1184. 
48. Kukovecz, Á.; Smajda, R.; Kónya, Z.; Kiricsi, I. Controlling the Pore Diameter Distribution of Multi-Wall Carbon Nanotube Buckypapers. Carbon 2007, 45, 1696-1716.

49. Whitby, R.L.D.; Fukuda, T.; Maekawa, T.; James, S.L.; Mikhalovsky, S.V. Geometric Control and Tuneable Pore Size Distribution of Buckypaper and Buckydiscs. Carbon 2008, 46, 949-956.

50. Das, R.K.; Liu, B.; Reynolds, J.R.; Rinzler, A.G. Engineered Macroporosity in Single-Wall Carbon Nanotube Films. Nano Lett. 2009, 9, 677-683.

51. Casavant, M.J.; Walters, D.A.; Scmidt, J.J.; Smalley, R.E. Neat Macroscopic Membranes of Aligned Carbon Nanotubes. J. Appl. Phys. 2003, 93, 2153-2156.

52. Wang, D.; Song, P.; Liu, C.; Wu, W.; Fan, S. Highly Oriented Carbon Nanotube Papers made of Aligned Carbon Nanotubes. Nanotechnology 2008, 19, 075609:1-075609:7.

53. Gonnet, P.; Liang, Z.; Choi, E.S.; Kadambala, R.S.; Zhang, C.; Brooks, J.S.; Wang, B.; Kramer, L. Thermal Conductivity of Magnetically Aligned Carbon Nanotube Buckypapers and Nanocomposites. Curr. Appl. Phys. 2006, 6, 119-122.

54. Hone, J.; Liaguno, M.C.; Nemes, N.M.; Johnson, A.T.; Fischer, J.E.; Walters, D.A.; Casavant, M.J.; Schmidt, J.; Smalley, R.E. Electrical and Thermal Transport Properties of Magnetically Aligned Single Wall Carbon Nanotube Films. Appl. Phys. Lett. 2000, 77, 666-668.

55. Lawson, K.W.; Lloyd, D.R. Membrane Distillation. J. Membr. Sci. 1997, 124, 1-25.

56. Hoang, M.; Bolto, B.; Tran, T. Desalination by Capacitive Deionisation. Water 2009, February, 63-66.

57. Pan, L.; Wang, X.; Zhang, Y.; Chen, Y.; Sun, Z. Electrosorption of Anions with Carbon Nanotube and Nanofibre Composite Film Electrodes. Desalination 2009, 244, 193-143.

58. Wang, X.; Li, M.; Chen, R.; Huang, S.; Pan, L.; Sun, Z. Electrosorption of Ions from Aqueous Solutions with Carbon Nanotubes and Nanofibers Composite Film Electrodes. Appl. Phys. Lett. 2006, 89, 053127.

59. Li, H.; Gao, Y.; Pan, L.; Zhang, Y.; Chen, Y.; Sun, Z. Electrosorptive Desalination by Carbon Nanotubes and Nanofibers Electrodes and Ion-Exchange Membranes. Water Res. 2008, 42, 4923-4928.

60. Dai, K.; Shi, L.; Zhang, D.; Fang, J. NaCl Adsorption in Multi-Walled Carbon Nanotube/Active Carbon Combination Electrode. Chem. Eng. Sci. 2006, 61, 428-433.

61. Viswanathan, G.; Kane, D.B.; Lipowicz, P.J. High Efficiency Fine Particulate Filtration Using Carbon Nanotube Coatings. Adv. Mater. 2004, 16, 2045-2049.

62. Kang, S.; Pinault, M.; Pfefferle, L.D.; Elimelech, M. Single-Walled Carbon Nanotubes Exhibit Strong Antimicrobial Activity. Langmuir 2007, 23, 8670-8673.

63. Brady-Esétvez, A.S.; Kang, S.; Elimelech, M.A. Single-Walled-Carbon-Nanotube Filter for Removal of Viral and Bacterial Pathogens. Small 2008, 4, 481-484.

64. Edwards, S.L.; Church, J.S.; Werkmeister, J.A.; Ramshaw, J.A.M. Tubular Micro-scale Multiwalled Carbon Nanotube-based Scaffolds for Tissue Engineering. Biomaterials 2009, 30, $1725-1731$.

65. Voher, U.; Zschoerper, N.P.; Koehne, Y.; Langowski, S.; Oehr, C. Plasma Modification of Carbon Nanotubes and Bucky Papers. Plasma Process. Polym. 2007, 4, S871-S877. 
66. Correa-Duarte, M.A.; Wagner, N.; Rojas-Chapana, J.; Morsczeck, C.; Thie, M.; Giersig, M. Fabrication and Biocompatibility of Carbon Nanotube-based 3D Networks as Scaffolds for Cell Seeding and Growth. Nano Lett. 2004, 4, 2233-2236.

67. Galvan-Garcia, P.; Keefer, E.K.; Yang, F.; Zhang, M.; Fang, S.; Zakhidov, A.A.; Baughman, R.H.; Romero, M. Robust Cell Migration and Neuronal Growth on Pristine Carbon Nanotube Sheets and Yarns. J. Biomater. Sci., Polym. Ed. 2007, 18, 1245-1261.

68. Hummer, G.; Rasalah, J.C.; Noworyta, J.P. Water Conduction through the Hydrophobic Channel of a Carbon Nanotube. Nature 2001, 414, 188-190.

69. Skoulidas, A.; Ackerman, D.M.; Johnson, K.; Sholl, D.S. Rapid Transport of Gases in Carbon Nanotubes. Phys. Rev. Lett. 2002, 89, 185901:1-185901:4.

70. Chen, H.; Johnson, J.K.; Sholl, D.S. Transport Diffusion of Gases is Rapid in Flexible Carbon Nanotubes. J. Phys. Chem. B 2006, 110, 1971-1975.

71. Waghe, A.; Rasaiah, J.C.; Hummer, G. Filling and Emptying Kinetics of Carbon Nanotubes in Water. J. Chem. Phys. 2002, 117, 10789-10795.

72. Noy, A.; Park, H.G.; Fornasiero, F.; Holt, J.K.; Grigoropoulos, C.P.; Bakajin, O. Nanofluidics in Carbon Nanotubes. Nanotoday 2007, 2, 22-29.

73. Corry, B. Designing Carbon Nanotube Membranes for Efficient Water Desalination. J. Phys. Chem. B 2008, 112, 1427-1434.

74. Thomas, J.A. and McGaughey, J.H. Reassessing Fast Water Transport through Carbon Nanotubes. Nano Lett. 2008, 8, 2788-2793.

75. Zheng, J.; Lennon, E.M.; Tsao, H. K.; Sheng, Y. J.; Jiang, S. Transport of a Liquid Water and Methanol Mixture through Carbon Nanotubes under a Chemical Gradient. J. Chem. Phys. 2005, 122, 214702:1-214702:7.

76. Striolo, A. The Mechanism of Water Diffusion in Narrow Carbon Nanotubes. Nano Lett. 2006, 6, 633-639.

77. Majumder, S.R.; Choudhury, N.; Ghosh, S.K. Enhanced Flow in Smooth Single-File Channel. J. Chem. Phys. 2007, 127, 054706:1-054706:5.

78. Allen, R.; Hansen, J.P.; Melchionna, S. Molecular Dynamics Investigation of Water Permeation through Nanopores. J. Chem. Phys. 2003, 119, 3905-3919.

79. Whitby, M.; Quirke, N. Fluid flow in Carbon Nanotubes and Nanopipes. Nature 2007, 2, 87-94.

80. Sun, L.; Crooks, R.M. Single Carbon Nanotube Membranes: A well-Defined Model for Studying Mass Transport through Nanoporous Materials. J. Am. Chem. Soc. 2000, 122, 12340-12345.

81. Miller, S.A.; Martin, C.R. Controlling the Rate and Direction of Electroosmotic Flow in Template-Prepared Carbon Nanotube Membranes. J. Electroanal. Chem. 2002, 522, 66-69.

82. Miller, S.A.; Young, V.Y.; Marin, C.R. Electroosmotic Flow in Template-Prepared Carbon Nanotube Membranes. J. Am. Chem. Soc. 2001, 123, 12335-12342.

83. Naguib, N.; Ye, H.; Gogotsi, Y.; Yazicioglu, A.G.; Megaridis, C.M.; Yoshimura, M. Observation of Water Confined in Nanometer Channels of Closed Carbon Nanotubes. Nano Lett. 2004, 4 , 2237-2243.

84. Rossi, M.P.; Ye, H.; Gogotsi, Y.; Babu, S.; Ndungu, P.; Bradley, J.-C. Environmental Scanning Electron Microscopy Study of Water in Carbon Nanopipes. Nano Lett. 2004, 4, 989-993.

85. Majumder, M.; Chopra, N.; Hinds, B.J. Effect of Tip Functionalization on Transport through Vertically Oriented Carbon Nanotube Membranes. J. Am. Chem. Soc. 2005, 127, 9062-9070. 
86. Nednoor, P.; Chopra, N.; Gavalas, V.; Bachas L.G.; Hinds, B.J. Reversible Biochemcial Switching of Ionic Transport through Aligned Carbon Nanotube Membranes. Chem. Mater. 2005, 17, 3593-3599.

87. Nednoor, P.; Gavalas, V.G.; Chopra, N.; Hinds, B.J.; Bachas, L.G. Carbon Nanotube Based Biomimetic Membranes: Mimicking Protein Channels regulated by Phosphorylation. J. Mater. Chem. 2007, 17, 1755-1757.

88. Majumder, M.; Zhan, X.; Andres, R.; Hinds, B.J. Voltage Gated Carbon Nanotube Membranes. Langmuir 2007, 23, 8624-8631.

89. Fornasiero, F.; Park, H.G.; Holt, J.K.; Stadermann, M.; Grigoropoulos, C.P.; Noy, A.; Bakajin, O. Ion Exclusion by Sub-2-nm Carbon Nanotube Pores. Proc. Natl. Acad. Sci. USA 2008, 0710437105:1-0710437105:6.

90. Holt, J.K.; Noy, A.; Huser, T.; Eaglesham, D.; Bakajin, O. Fabrication of a Carbon NanotubeEmbedded Silicon Nitride Membrane for Studies of Nanometer-Scale Mass Transport. Nano Lett. 2004, 4, 2245-2250.

91. Sears, K.; Schütz, J.; Huynh, C.; Hawkins, S.; Humphries, W. Evaluation and characterisation of carbon nanotube membranes. In Proceedings of the 2008 International Conference On Nanoscience and Nanotechnology (ICONN), Melbourne, Australia, 25-27 February 2008; p. 37.

92. Murakami, Y.; Chiashi, S.; Einarsson, E.; Maruyaman, S. Polarization Dependence of Resonant Raman Scattering from Vertically Aligned Single-Walled Carbon Nanotube Films. Phys. Rev. B: Condens. Matter Mater. Phys. 2005, 71, 085403:1-085403:8.

93. Duesberg, G.S.; Loa, I.; Burghard, M.; Syassen, K.; Roth, S. Polarized Raman Spectroscopy on Isolated Single-Wall Carbon Nanotubes. Phys. Rev. Lett. 2000, 85, 5436-5439.

94. Gommans, H.H.; Alldredge, J.W.; Tashiro, H.; Park, J.; Magnuson, J. Fibers of Aligned SingleWalled Carbon Nanoutbes: Polarized Raman Spectroscopy. J. Appl. Phys. 2000, 88, 2509-2514.

95. Yu, M.; Funke, H.H.; Falconer, J.L.; Noble, R.D. High Density, Vertically-Aligned Carbon Nanotube Membranes. Nano Lett. 2009, 9, 225-229.

96. Futaba, D.N.; Hata, K.; Yamada, T.; Hiraoka, T.; Hayamizu, Y.; Kakudate, Y.; Tanaike, O.; Hatori, H.; Yumura, M.; Iijima, S. Shape-Engineerable and Highly Densely Packed SingleWalled Carbon Nanotubes and Their Application as Super-Capacitor Electrodes. Nature 2006, 5 , 987-994.

97. Chakrapani, N.; Wei, B.; Carrillo, A.; Ajayan, P.M.; Kane, R.S. Capillarity-Driven Assembly of Two-Dimensional Cellular Carbon Nanotube Foams. Proc. Natl. Acad. Sci. USA 2004, 101, 4009-4012.

98. Jung, H.Y.; Jung, S.M.; Gu, G.H.; Suh, J.S. Anodic Aluminum Oxide Membrane Bonded on a Silicon Wafer for Carbon Nanotube Field Emitter Arrays. Appl. Phys. Lett. 2006, 89, 013121:1-013121:3.

99. Velleman, L.; Shapter, J.G.; Losic, D. Gold Nanotube Membranes Functionalised with Fluorinated Thiols for Selective Molecular Transport. J. Membr. Sci. 2009, 328, 121-126.

(C) 2010 by the authors; licensee Molecular Diversity Preservation International, Basel, Switzerland. This article is an open-access article distributed under the terms and conditions of the Creative Commons Attribution license (http://creativecommons.org/licenses/by/3.0/). 